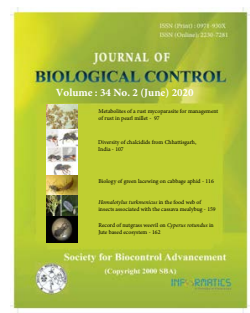

Research Article

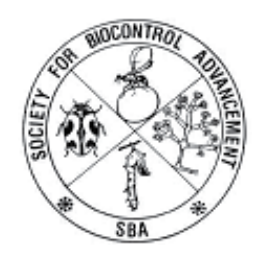

\title{
Biology of green lacewing, Chrysoperla zastrowi sillemi (Esben-Petersen) on cabbage aphid, Brevicoryne brassicae L.
}

P. SREE CHANDANA ${ }^{1 *}$, ANIL SOOD ${ }^{2}$ and P. L. SHARMA

${ }^{1}$ Department of Entomology, ${ }^{2}$ Directorate of Extension Education, Dr. Y. S. Parmar University of Horticulture and Forestry, Nauni, Solan - 173230, Himachal Pradesh, India

*Corresponding author E-mail: sreechandana.4157@gmail.com

\begin{abstract}
Laboratory experiments were conducted at Department of Entomology, Dr. Y. S. Parmar University of Horticulture and Forestry, Nauni, Solan, Himachal Pradesh, India during 2019-20 to study the biology of green lacewing, Chrysoperla zastrowi sillemi (Esben-Petersen) on cabbage aphid, Brevicoryne brassicae L. The aphid culture was maintained on cabbage seedlings and the predator, $C$. zastrowi sillemi was reared on aphids. Duration of different developmental stages of the predator as well as adult longevity and sex ratio were recorded. The mean egg, larval and pupal periods were $4.82 \pm 0.24,11.2 \pm 0.60$ and $7.03 \pm 0.29$ days, respectively. The total developmental period was $21.4 \pm 0.51$ days. Larva of $C$. zastrowi sillemi had undergone three instars before pupation. The first instar had the shortest duration ( $3.80 \pm 0.20$ days) while the third instar lasted for longest period ( $4.25 \pm 0.15$ days). The pre oviposition, oviposition and total longevity of female adult were $6.60 \pm 0.40,25.40 \pm 0.51$ and $40.8 \pm 1.28$ days, respectively while longevity of male adult of C. zastrowi sillemi was $29.40 \pm 1.86$ days. The studies proved that predator, $C$. zastrowi sillemi could complete the life cycle on the cabbage aphid in about 20-23 days and can serve as a potential biocontrol agent to manage this pest.
\end{abstract}

KEY WORDS: Biocontrol agent, Brevicoryne brassicae, cabbage, Chrysoperla zastrowi sillemi, life cycle

(Article chronicle: Received: 16-03-2020; Revised: 12-05-2020; Accepted: 16-05-2020)

\section{INTRODUCTION}

The green lacewing, Chrysoperla zastrowi sillemi (Esben-Petersen) (Neuroptera: Chrysopidae), is a polyphagous predator with great potential for contributing to biological control. The predator in its larval stage predates on several soft bodied insects like aphids, scales, leafhoppers, whiteflies, psyllids, thrips, mealybugs, lepidopterans, mites etc. (Principi and Canard 1984). Adults are pale green with long antennae and transparent, pale green wings which feed only on pollen, nectar and honeydew (Kubavat et al., 2017). The efficacy of C. zastrowi sillemi in the biological control of aphids, besides other arthropod pests, has been well studied and documented (Senior and McEwen, 2001). With the growing awareness and concern for food safety and environment pollution, the use of biocontrol agents in pest suppression has been gaining importance especially in vegetable crops where pesticide residues are a major concern. In order to implement a biological control program by releasing an insect predator, it is very essential to understand its biology or life cycle on the target prey species to assess its suitability and predating efficiency.

Cabbage aphid, Brevicoryne brassicae L. is a major sucking pest on cabbage, an important vegetable crop of both tropical and temperate regions. Nymphs and adults colonize between leaf whorls and suck the sap from foliage. Aphid infestation results in discoloration of cabbage head and development of black sooty mould which render the head unsuitable for marketing and consumption. In order to manage aphids, insecticides are commonly used which pose serious health and environmental hazards besides contributing to build up of resistance in pest populations. Hence, non chemical means of pest management is highly desirable. Since cabbage is an important vegetable crop of temperate regions like Himachal Pradesh where organic farming is becoming popular, it is very relevant to standardize biocontrol strategies against major pests. Though there are studies and reports on the biology of C. zastrowi sillemi on different aphid and other prey species (Sharma and Verma, 1991; Abd-Rabou, 2008; Qureshi and Stasly, 2009; Chakraborty et al., 2011), there are not many studies on cabbage aphid under Solan conditions. In this background, present experiments were carried out to study the biology and development of C. zastrowi sillemi on cabbage aphid.

\section{MATERIALS AND METHODS}

Laboratory experiments were conducted in the 
Department of Entomology, Dr. Y. S. Parmar University of Horticulture and Forestry, Nauni, Solan, Himachal Pradesh during 2019-20 to study the biology and development of Chrysoperla zastrowi sillemi on the cabbage aphid. For this purpose, both prey (B. brassicae) and predator (C. zastrowi sillemi) were reared in the laboratory under controlled conditions of $28 \pm 2^{\circ} \mathrm{C}$ temperature and $65-70 \%$ relative humidity.

\section{Maintenance of insect cultures \\ Rearing of Brevicoryne brassicae under laboratory con- ditions}

The cabbage seedlings were raised in plastic pots under laboratory conditions. The aphid colonies collected from naturally infested cabbage field were released and maintained on the laboratory grown cabbage plants. The aphid colonies on these plants were used as stock culture of prey for rearing predator as well as conducting biology studies.

\section{Rearing of Chrysoperla zastrowi sillemi}

The initial culture of eggs of C. zastrowi sillemi was procured from ICAR-National Bureau of Agricultural Insect Resources, Bengaluru, Karnataka, India. These eggs were transferred into the Petri plates for hatching. After hatching, the larvae were collected and released into individual Petri plates. They were provided with cabbage aphids that are reared in the laboratory. The larvae of predator were thus reared till pupation. The pupae were collected and transferred to plastic jars for the adult emergence. The adults emerged from pupae were transferred to the Chrysoperla oviposition cages. The freshly laid eggs were collected daily. The predator was thus reared for two generations on cabbage aphid before using for biology studies in order to overcome the effect of the previous host.

\section{Biological parameters studied}

Eggs of C. zastrowi sillemi were collected from the stock culture and transferred into individual vials and were observed daily for hatching. On hatching, the larvae were reared on the cabbage aphid, B. brassicae until pupation. Once larvae entered pupation, they were observed till adult emergence. The adults thus emerged were released into the oviposition cages. Cotton swabs drenched with honey solution (50\%), protinex mixture (protinex, pollen, honey and yeast) and water were provided as diet to the adults. Two hundred and fifty freshly laid eggs of C. zastrowi sillemi were collected from the oviposition cages and kept in five Petri dishes with a set of 50 eggs in each Petri dish as a replicate and five replications were maintained. The duration of different life stages (egg, larva, pupa, adult) of C. zastrowi sillemi was recorded. In addition, durations of pre-oviposition (the number of days taken by the female adults from the day of emergence till the day of first egg laying), oviposition (the number of days during which the adult female laid eggs) and post-oviposition (period after oviposition till the death of adult) were also recorded. Besides these, the longevity of male and female adults, sex ratio (proportion of females to total number of adults emerged) and total life cycle duration were also recorded.

\section{RESULTS AND DISCUSSION}

\section{Egg}

Eggs were white with a characteristic stalk, laid singly by female adult of green lacewing (Plate $1 \mathrm{a}$ and $\mathrm{b}$ ). The incubation period of C. zastrowi sillemi ranged from 4 to 5 days with an average of $4.82 \pm 0.24$ days (Table 1). Similar range of egg period was reported even when C. carnea was reared on sterilized eggs of laboratory host, Corcyra cephalonica (Subhan et al., 2010). The present results are also in conformity with the findings of Patro and Behera (2002) who reported the egg period of $C$. carnea as $4.01 \pm 0.05$ days when fed with $A$. craccivora and 4.8 days when fed with $A$. gossypii (Afzal and Khan, 1978). It indicates that incubation period of $C$. zastrowi was not significantly affected by the host species.

\section{Larva}

The larval stage of C. zastrowi sillemi passed through three instars (Plate 1c, $d$ and e). The number of instars was differentiated based on the moulted skin. The newly emerged first instar larva was pale green in color and as it moulted into second and third instar, the color changed from light brown to dark brown. The total larval period ranged from 10-13 days with an average of $11.2 \pm 0.6$ days (Table 1 ). The duration of first, second and third larval instars ranged from 3 to 4,3 to 5 and 4 to 5 days, respectively. The mean durations of the respective instars were $3.80 \pm 0.2,4.00 \pm 0.15$ and $4.25 \pm$ 0.15 days. It was observed that the larva remained relatively shorter period as first instar compared to the latter instars. These results are in agreement with those of earlier workers who reported that the total larval period of C. carnea as 11.37 and 11.00 days, respectively when fed with larvae of $H$. armigera and mixed host diet. The total larval period was reported as 11.15 days on neonate of $H$. armigera (Turkhade et al., 2010) and 11.64 days on eggs of S. cereallela (Khan et al., 2005) which is similar to the present findings.

\section{Pupa}

The third instar larvae started to spin cocoon which were round and white in colour (Plate 1f). The pupal period ranged from 6 to 7.5 days with an average of $7.03 \pm 0.29$ days (Table 1). Similar range of pupal period of C. zastrowi sillemi was 
Table 1. Duration of developmental stages of Chrysoperla zastrowi sillemi on Brevicoryne brassicae

\begin{tabular}{|c|c|c|c|}
\hline \multirow{2}{*}{\multicolumn{2}{|c|}{ Developmental stage }} & \multicolumn{2}{c|}{ Duration (days) } \\
\cline { 2 - 4 } & Range & Mean \pm SE \\
\hline \multirow{2}{*}{ Larva } & First instar & $3-4$ & $3.80 \pm 0.20$ \\
\cline { 2 - 4 } & Second instar & $3-5$ & $4.00 \pm 0.15$ \\
\cline { 2 - 4 } & Third instar & $4-5$ & $4.25 \pm 0.15$ \\
\hline \multicolumn{2}{|c|}{ Total larval period } & $10-13$ & $11.20 \pm 0.60$ \\
\hline \multicolumn{2}{|c|}{ Pupal period } & $6-7.5$ & $7.03 \pm 0.29$ \\
\hline \multicolumn{2}{|c|}{ Total developmental period } & $20-23$ & $21.40 \pm 0.51$ \\
\hline
\end{tabular}

also reported by Satpathy et al. (2012) on Aphis gossypii, Sattar et al. (2011) on Pectinophora gossypiella, Turkhade et al. (2010) on neonate larvae of $H$. armigera and Balakrishnan et al. (2005) on Amrasca devastans.

\section{Total developmental Period}

It is evident from the data presented in Table 1 that the total developmental period of $C$. zastrowi sillemi on the cabbage aphid, B. brassicae, from egg to adult emergence, ranged from 20 to 23 days with an average of $21.4 \pm 0.51$ days. This comprised of $4.82 \pm 0.24$ days of incubation, $11.2 \pm$ 0.60 days of larval stage and $7.03 \pm 0.29$ days of pupal period. These results are in conformity with the findings of Tesfye and Gautam (2002) who reported the total development period of C. carnea as 21.35 days when fed with $A$. craccivora. Vivek et al. (2013) found that the total life cycle of $C$. carnea was completed in 20.5 days on C. cephalonica and 24.2 days on Lipaphis erysmi.

\section{Oviposition period}

A perusal of data presented in Table 2 revealed that the pre-oviposition, oviposition and post-oviposition periods of female adult of $C$. zastrowi sillemi developed from larvae fed with $B$. brassicae ranged from 5 to 7,8 to 27 and 5 to 13 days, respectively. The corresponding mean values of these periods were $6.6 \pm 0.4,25.4 \pm 0.52$ and $9.9 \pm 1.46$ days, respectively.

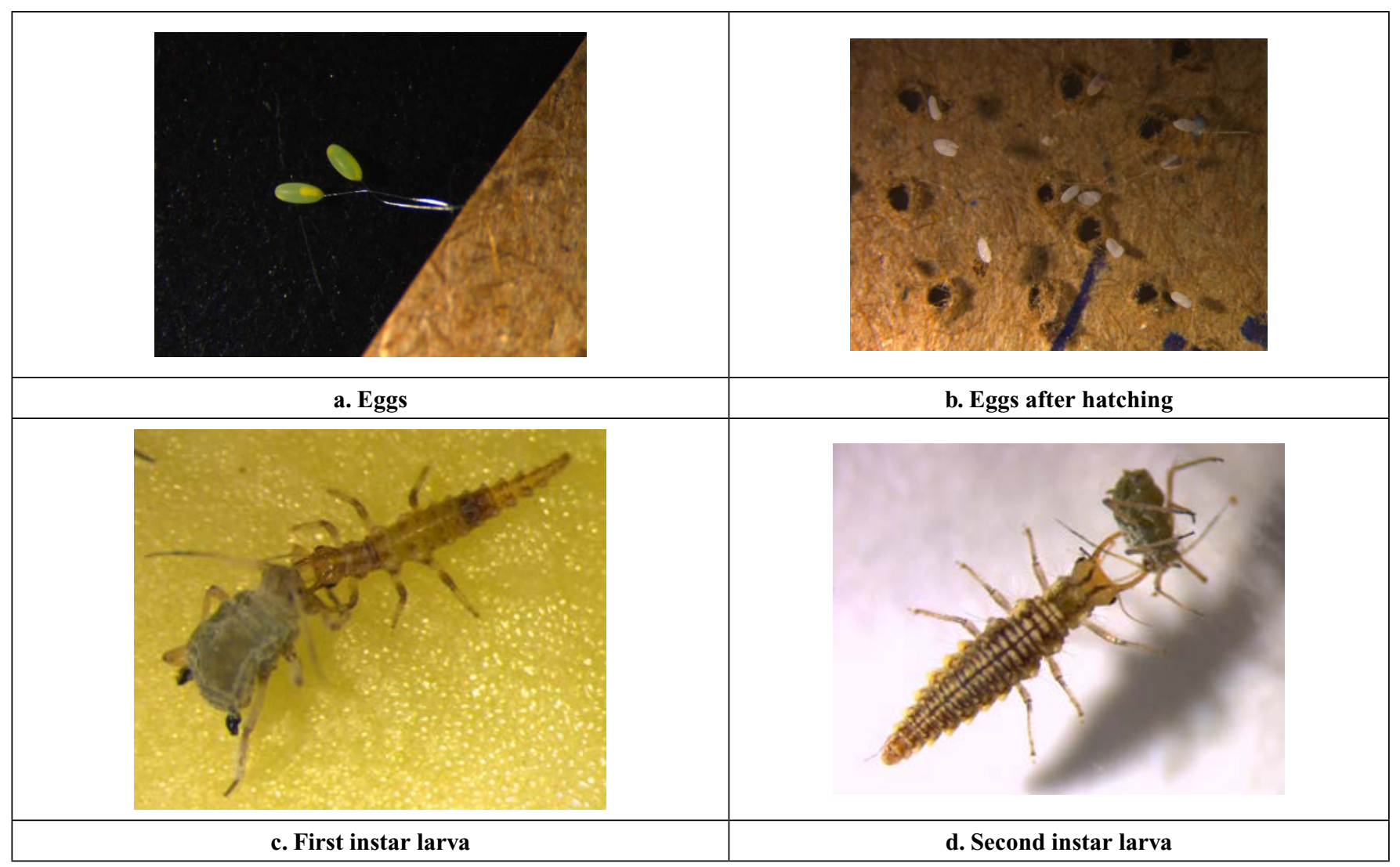




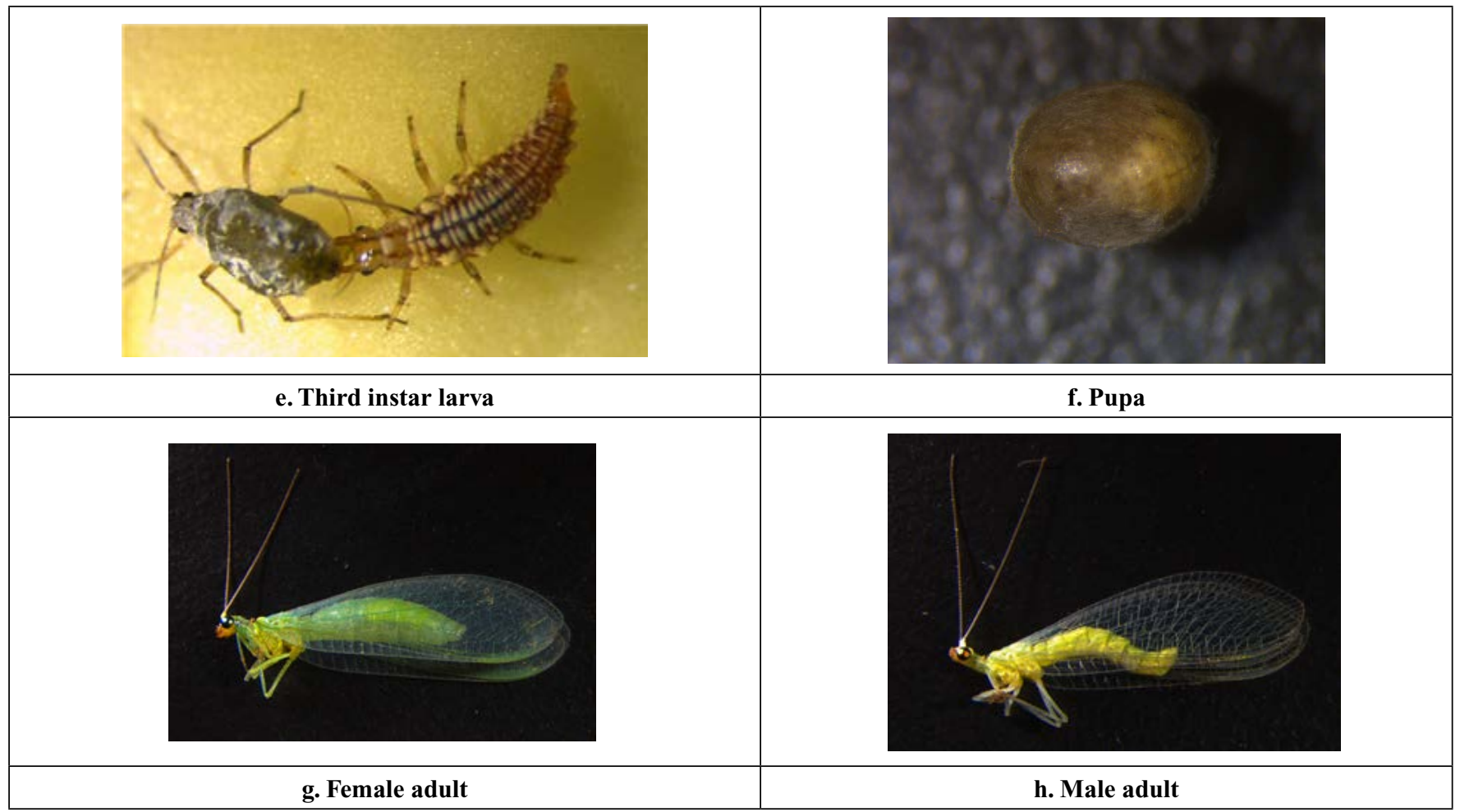

Plate 1. Life stages of Chrysoperla zastrowi sillemi

Table 2. Duration of reproductive stages and longevity of adults of Chrysoperla zastrowi sillemi reared on Brevicoryne brassicae

\begin{tabular}{|c|c|c|c|c|}
\hline \multirow{2}{*}{$\begin{array}{c}\text { S. } \\
\text { No. }\end{array}$} & \multirow{2}{*}{ Stage/Parameter } & \multicolumn{2}{|c|}{ Duration (days) } \\
\cline { 3 - 4 } 1 & \multicolumn{2}{|c|}{ Range } & Mean \pm SE \\
\hline 2 & \multicolumn{2}{|c|}{ Ore-oviposition period } & $5-7$ & $6.60 \pm 0.40$ \\
\hline 3 & Post oviposition period & $8-27$ & $25.40 \pm 0.51$ \\
\hline \multirow{2}{*}{4} & Adult longevity & Male & $25-35$ & $29.40 \pm 1.86$ \\
\cline { 3 - 5 } & & Female & $39-44$ & $40.80 \pm 1.28$ \\
\hline 5 & Total life cycle & $58-69$ & $64.95 \pm 3.51$ & \\
\hline
\end{tabular}

It revealed that the female adult mated and started laying eggs within a week after emergence. These results are in conformity with those of Mannan et al. (1997), who recorded the pre-oviposition, oviposition and post-oviposition periods of C. zastrowi sillemi on A. gossypii and M. persicae as $6.55,21.10$ and 7.95 days, and 9.25, 21.85 and 11.20 days, respectively. However, Subhan et al. (2010) reported a shorter pre-oviposition period of 2.20 days and slightly longer oviposition periods of 32.90 days of C. zastrowi when reared on C. cephalonica.

\section{Adult longevity}

There were significant differences in the longevity of male and female adults of C. zastrowi sillemi (Table 2). In case of male, it ranged from 25 to 35 days, while the life span of female adult varied from 39 to 44 days. The mean longevity of male adults was $29.4 \pm 1.86$ days while it was $40.8 \pm 1.28$ days in case of females. Hence, it can be inferred that female adults lived longer than their male counterparts. This is a desirable feature as females contribute to offspring development which is crucial for successful biocontrol program. The present findings are in conformity with those of Dhepe (2001) who recorded the female longevity as 40.12 days on the cabbage aphid and male longevity of the predator as 29.73 days on the cotton aphid and 29.11 days on the safflower aphid. The adult longevity reported by the earlier workers was 36.67 days on unsterilized eggs of $C$. cephalonica, 49.67 days on neonate of $H$. armigera (Khulbeet $a l ., 2005$ ) and 16.56 days on eggs of $S$. cerealllea (Khan et al., 2005). According to Jagadish and Jayaramaiah (2004), the male and female longevity were 11.50 and 34.25 days when larvae raised on the tobacco aphid.

The present study revealed that green lacewing, $C$. zastrowi sillemi had successfully completed its life cycle on the cabbage aphid in about 20-23 days. The larva undergone three instars before pupation. The fitness of off springs and duration of developmental stages were at par with earlier reports on the biology of this predator on other preys. Hence, it can be inferred that $C$. zastrowi sillemi could be used as an effective predator of cabbage aphid, B. brassicae and can be included as a component of integrated pest management in cabbage. 


\section{ACKNOWLEDGEMENT}

The authors are thankful to the Director, ICAR- National Bureau of Agricultural Insect Resources, Bengaluru for providing the initial stock culture of predator, Chrysoperla species.

\section{REFERENCES}

Abd-Rabou S. 2008. Evaluation of the green lacewing, Chrysoperla carnea (Stephens) (Neuroptera: Chrysopidae) against aphids on different crops. J Biol Control 22:299-310.

Afzal M, Khan MR. 1978. Life history and feeding behavior of green lacewing, Chrysoperla carnea Steph. (Neuroptera: Chrysopidae). Pakistan J Zool. 10:83-90.

Balakrishnan N, Baskaran RKM, Mahadevan NR. 2005. Development and predatory potential of green lacewing, Chrysoperla carnea (Stephens) (Neuroptera:Chrysopidae) on different prey insects. Agric Sci Digest 25:194-7.

Chakraborty D, Korat DM, Deb S. 2011. Observations on the behaviour of the green lacewing, Chrysoperla zastrowi sillemi (Esben-Peterson). pp. 399-403. In: Dunston P, Ambrose (Eds.). Insect Pest Management, A. Current Scenario. Entomology Research Unit, St. Xavier's College: Palayamkottai, India; p. 399-403.

Dhepe VR. 2001. Studies on biology of Chrysoperla zastrowi sillemi (Esben-Petersen) on different hosts. M.Sc. (Agri.) dissertation submitted to Dr. Punjabrao Deshmukh Krishi Vidhyapeeth, Akola, Maharashtra, India (Unpublished).

Jagadish KS, Jayaramaiah M. 2004. Biology and predatory potentiality of Chrysoperla carnea on the tobacco aphid, Myzus nicotianae (Homoptera). J Ecobiol. 16:161-7.

Khan MIN, Naeem M, Salihah Z, Sattar A, Farid A. 2005. Development of Chrysoperla carnea (Stephens) on eggs and etherised adults of Sitotroga cerealella (Olivier). Sarhad J Agric. 21:265-70.

Khulbe P, Maurya RP, Khan MA. 2005. Biology of Chrysoperla carnea (Stephens) on different host insects. Ann Plant Prot Sci. 13:351-4.

Kubavat AK, Jethva DM, Wadaskar PS. 2017. Biology and feeding potential of Chrysoperla zastrowi sillemi (Esben-Peterson) on eggs of Corcyra cephalonica (Stainton). Environ Ecol. 35:1948-52.
Lohar MK, Memon H, Bukero A. 2005. Biology and feeding potential of green lacewing, Chrysoperla carnea Stephens (Neuroptera: Chrysopidae) on mustard aphid. Proc Pakistan Cong Zool. 25:57-63.

Mannan V, Varma GC, Brar KS. 1997. Biology of Chrysoperla carnea (Steph) on Aphis gossypii Glover and Myzus persicae (Suler). J Insect Sci. 10:143-45.

Patel SM, Radadia GG, Pandya HV, Patel SD, Dane PP. 2015. Comparative biology and predatory potential of green lacewing on different aphid species. Int J Plant Prot. 8:13-20. https://doi.org/10.15740/HAS/IJPP/8.1/13-20.

Patro B, Behera MK. 2002. Biology and feeding potential of Chrysoperla carnea (Stephens) (Neuroptera: Chrysopidae) on the bean aphid, Aphis craccivora Koch. J Biol Control 16:77-9.

Principi MM, Canard M. 1984. Feeding habits. pp. 76-91. In: Canard M, Semeria Y and New TR (Eds.). Biology of Chrysopidae. The Hague: Dr W. Junk Publishers.

Qureshi JA, Stansly PA. 2009. Exclusion techniques reveal significant biotic mortality suffered by Asian citrus psyllid, Diaphorina citri (Hemiptera: Psyllidae) populations in Florida citrus. Biol Control 50:129-36. https://doi.org/10.1016/j.biocontrol.2009.04.001.

Satpathy S, Kumar A, Shivalingaswamy TM, Rai AB. 2012. Effect of prey on predation, growth and biology of green lacewing (Chrysoperla zastrowi sillemi). Indian J Agric Sci. 82:55-8.

Sattar M, Abro GH. 2011. Mass rearing of Chrysoperla carnea (Stephens) (Neuroptera: Chrysopidae) adults for integrated pest management programmes. Pakistan J Zool. 43:483-7.

Senior LJ, McEwen PK. 2001. The use of lacewings in biological control. pp. 296-302. In: McEwen PK, New TR, Whittington AE (Eds.). Lacewings in the crop environment. Cambridge University Press: Cambridge. https://doi.org/10.1017/CBO9780511666117.014.

Sharma PK, Verma VK. 1991. Biology of Chrysoperla carnea (Stephens) (Neuroptera: Chrysopidae) in Himachal Pradesh. J Biol Control 5:81-4.

Subhan S, Shetgar SS, Patait DD, Badjugar AG, Dhurgude SS. 2010. Biology of Chrysoperla carnea (Stephens) on Corcyra cephalonica (Stainton). Indian J Entomol. 72:251-5. 
Biology of green lacewing on cabbage aphid

Tesfaye A, Gautam RD. 2002. Biology and feeding potential of green lacewing, Chrysoperla carnea on non-rice moth prey. Indian J Entomol. 64:457-64.

Turkhade PD, Undirwade DB, Deshpande PP, Kardale SA. 2010. Biology and predatory potential of Chrysoperla carnea on aphids, citrus psylla and neonate Noctuids. Green Farming 1: 400-03.
Vivek S, Paul B, Pandi GGP, Shankarganesh K. 2013. Biology and predatory potential of green lacewing, Chrysoperla zastrowi sillemi (Carnea-group) on different aphid species. Ann Plant Prot Sci. 21:9-21. 